\title{
Naïri Nahapétian, Qui a tué l'ayatollah Kanuni?
}

\section{Veronica Amadessi}

\section{Q OpenEdition}

\section{Journals}

\section{Edizione digitale}

URL: http://journals.openedition.org/studifrancesi/7072

DOI: ERREUR PDO dans /localdata/www-bin/Core/Core/Db/Db.class.php L.34 : SQLSTATE[HY000]

[2006] MySQL server has gone away

ISSN: 2421-5856

\section{Editore}

Rosenberg \& Sellier

\section{Edizione cartacea}

Data di pubblicazione: 1 septembre 2010

Paginazione: $420-421$

ISSN: 0039-2944

\section{Notizia bibliografica digitale}

Veronica Amadessi, «Naïri Nahapétian, Qui a tué l'ayatollah Kanuni?», Studi Francesi [Online], 161 (LIV I

II) | 2010, online dal 30 novembre 2015, consultato il 07 janvier 2021. URL: http://

journals.openedition.org/studifrancesi/7072 ; DOI: https://doi.org/10.4000/studifrancesi.7072

Questo documento è stato generato automaticamente il 7 janvier 2021.

\section{(c) (i) (9)}

Studi Francesi è distribuita con Licenza Creative Commons Attribuzione - Non commerciale - Non opere derivate 4.0 Internazionale. 


\title{
Naïri Nahapétian, Qui a tué l'ayatollah Kanuni?
}

\author{
Veronica Amadessi
}

\section{NOTIZIA}

NAÏRI NAHAPÉTIAN, Qui a tuél'ayatollah Kanuni?, Paris, Liana Levi, 2009, pp. 278.

1 Narek Djamshid, un giovane studente emigrato in Francia da bambino, si trova a Teheran per redigere un articolo sulle elezioni presidenziali. Il ragazzo cerca di ottenere informazioni sul sistema politico iraniano da una femminista islamica, Leila, che lo porta con sé al Palazzo di Giustizia per consegnare un fascicolo. Mentre i due si trovano all'interno del tribunale, l'ayatollah Kanuni, potente e odiatissimo giudice iraniano che dovrebbe ricevere Leila, viene assassinato. Comincia allora un'avventura rocambolesca, durante la quale Narek porta avanti l'inchiesta incontrando personaggi caricaturali ed enigmatici. La ricerca dell'assassino diventa ben presto una scusa per parlare dell'attuale società iraniana, del suo sistema politico, delle sfaccettature che la contraddistinguono. Le ragioni dell'omicidio passano, in realtà, in secondo piano, ed il narratore si concentra sul complesso sistema che dirige il paese natale di Narek e sulle sfumature, anche impercettibili, che fanno dell'Iran un paese pieno di contraddizioni.

2 L'autrice, una giovane giornalista iraniana emigrata in Francia, offre con questo primo romanzo uno spaccato dell'Iran odierno, della sua vita politica, del fermento intellettuale che cova sotto la paura. Il lettore può restare deluso dal modo in cui vengono portate avanti le indagini, poiché questo, più che un vero e proprio romanzo giallo, è un trattato sulla società iraniana e sui suoi problemi travestito da polar. Questo spiega il finale non convenzionale del romanzo (il lettore non saprà chi ha ucciso il giudice), e l'insistenza del narratore su certe considerazioni di carattere sociologico e storico. Pur non rispondendo all'interrogativo del titolo, questo tentativo sperimentale di associare forme letterarie diverse appare interessante; lo stile scorrevole, i dialoghi e le descrizioni dettagliate lasciano trasparire una sviluppata capacità di osservazione e 
riflessione. I contenuti vanno al di là degli stereotipi per proporre un'immagine più vera dell'Iran. Il volume è arricchito da una terminologia finale e da una cronologia che trasformano il romanzo, situandolo a metà strada tra fiction e reportage giornalistico. 